\title{
DOSTOSOWANIE INSTRUMENTÓW NARODOWEGO BANKU POLSKIEGO DO STANDARDÓW EUROSYSTEMU - OPERACJE OTWARTEGO RYNKU
}

\section{WSTĘP}

Operacje otwartego rynku (OOR) są podstawową formą interweniowania banku centralnego na rynku pieniężnym. Definiuje się je jako zakup i sprzedaż przez bank centralny papierów wartościowych publicznych i prywatnych, dopuszczonych do tych operacji ${ }^{1}$. Współcześnie banki centralne w ramach operacji otwartego rynku wykorzystują również instrumenty, które papierami wartościowymi nie są, np. depozyty w banku centralnym czy swapy walutowe.

Operacje otwartego rynku prowadzone są zawsze $z$ inicjatywy banku centralnego na podstawie analizy płynnościowej rynku lub analizy popytu zgłaszanego przez banki. Spośród klasycznej triady instrumentów (operacje otwartego ryn$\mathrm{ku}$, operacje kredytowo-depozytowe oraz rezerwa obowiązkowa) są one $\mathrm{z}$ reguly najbardziej zyskowne dla banków komercyjnych, dlatego korzystają z nich najchętniej. Służą one do regulowania płynności systemu bankowego i tym samym pośrednio wpływają na kształtowanie się krótkoterminowej stopy procentowej na rynku pieniężnym. Bank centralny, ustalając stopę podstawowych operacji otwartego rynku, oddziałuje na oprocentowanie depozytów na rynku międzybankowym o zbliżonym okresie zapadalności. Oprocentowanie to z kolei kształtuje poziom stóp procentowych instrumentów długoterminowych, oczekiwania inflacyjne oraz kurs walutowy ${ }^{2}$. W ramach operacji otwartego rynku bank centralny kupuje (sprzedaje) papiery wartościowe lub waluty od banków komercyjnych, co

\footnotetext{
${ }^{1}$ Z. Fedorowicz, Polityka pieniężna, Poltext, Warszawa 1997, s. 23.

${ }^{2}$ M. Cendal, Instrumenty polityki pieniężnej, [w:] W. Przybylska-Kapuścińska (red.), Wspótczesna polityka pieniężna, Difin, Warszawa 2008, s. 122.
} 
zwiększa (zmniejsza) środki na ich rachunkach bieżących. Płynne rezerwy systemu bankowego rosną (maleją).

Idea Eurosystemu wymaga, aby państwa wchodzące do strefy euro miały jednolity system instrumentów polityki pieniężnej, w tym operacji otwartego rynku (OOR). Harmonizacji ze standardami Europejskiego Banku Centralnego (EBC) wymagają wszystkie rodzaje operacji na otwartym rynku przeprowadzone przez Narodowy Bank Polski (NBP). Opracowanie przedstawia analizę porównawczą rozwiązań polskich i tych stosowanych w euroobszarze w zakresie operacji otwartego rynku. Celem tej analizy jest określenie stopnia dostosowania omawianego instrumentu wykorzystywanego przez NBP do standardów, norm i procedur EBC. Tekst składa się z dwóch części. Pierwsza nakreśla istotę i konstrukcję oraz sposób działania operacji otwartego rynku w Eurosystemie, druga - w Polsce. Wnioski prezentują stopień harmonizacji tych dwóch rozwiązań oraz proponowane kierunki zmian dostosowawczych.

\section{OPERACJE OTWARTEGO RYNKU W EUROOBSZARZE}

Podstawą prawną przeprowadzania operacji otwartego rynku w Eurosystemie jest Protokót w sprawie Statutu Europejskiego Systemu Banków Centralnych i Europejskiego Banku Centralnego. W jego myśl ECB oraz krajowe banki centralne mogą dokonywać między sobą operacji na rynku finansowym poprzez zawieranie umów kupna albo sprzedaży bezwarunkowej lub warunkowej czy poprzez zaciąganie (udzielanie) pożyczek w formie wierzytelności, papierów podlegających obrotowi rynkowemu lub walut ${ }^{3}$.

Europejski Bank Centralny przeprowadza standardowo cztery rodzaje operacji otwartego rynku, które różnią się między sobą pod względem celu, regularności i procedur. Są nimi: podstawowe operacje refinansujące (main refinancing operations - MRO), dłuższe operacje refinansujące (longer-term refinancing operations - LTRO), operacje dostrajające (fine-tuning operations) oraz operacje strukturalne (structural operations). Tabela 1 prezentuje rodzaje i formy operacji otwartego rynku w Eurosystemie.

Podstawowe operacje refinansujące to najważniejsze operacje otwartego rynku prowadzone przez EBC. Spełniają one następujące funkcje:

- ich oprocentowanie (Main Refinancing Rate, MRR) jest kluczową stopą procentową Eurosystemu ${ }^{4}$, gdyż wyznacza akceptowany na przetargu poziom

\footnotetext{
${ }^{3}$ Protocol on the Statute of European System of Central Banks and of the European Central Bank, art. 1.

${ }^{4}$ Średnia ważona stopa transakcyjna overnight - EONIA kształtuje się w pobliżu stopy MRR.
} 
stóp procentowych i łagodzi wahania krótkoterminowych rynkowych stóp procentowych;

- zapewniają refinansowanie, co pomaga w zarządzaniu płynnością na rynku;

- sygnalizują nastawienie w polityce pieniężnej ${ }^{5}$.

Ze względu na sytuację płynnościową w Eurosystemie są to operacje zasilające w płynność (repo), przeprowadzane regularnie co tydzień (we wtorek), w sposób zdecentralizowany przez krajowe banki centralne, w formie przetargów standardowych (aukcji amerykańskiej). Zazwyczaj mają tygodniowy termin zapadalności, choć w zależności od dni wolnych od pracy w państwach członkowskich termin ten może być inny ${ }^{6}$. Dostęp do MRO mają wszystkie instytucje kredytowe spełniające ogólne kryteria kwalifikujące (general eligibility criteria), czyli:

- podlegające rezerwie obowiązkowej zgodnie z artykułem 19 Protokotu w sprawie Statutu Europejskiego Systemu Banków Centralnych i Europejskiego Banku Centralnego,

- cechujące się dobrą kondycją finansową,

- spełniające operacyjne kryteria ustalone przez poszczególne krajowe banki centralne ${ }^{7}$.

Zabezpieczeniem podstawowych operacji refinansujących są kwalifikowane aktywa rynkowe i nierynkowe.

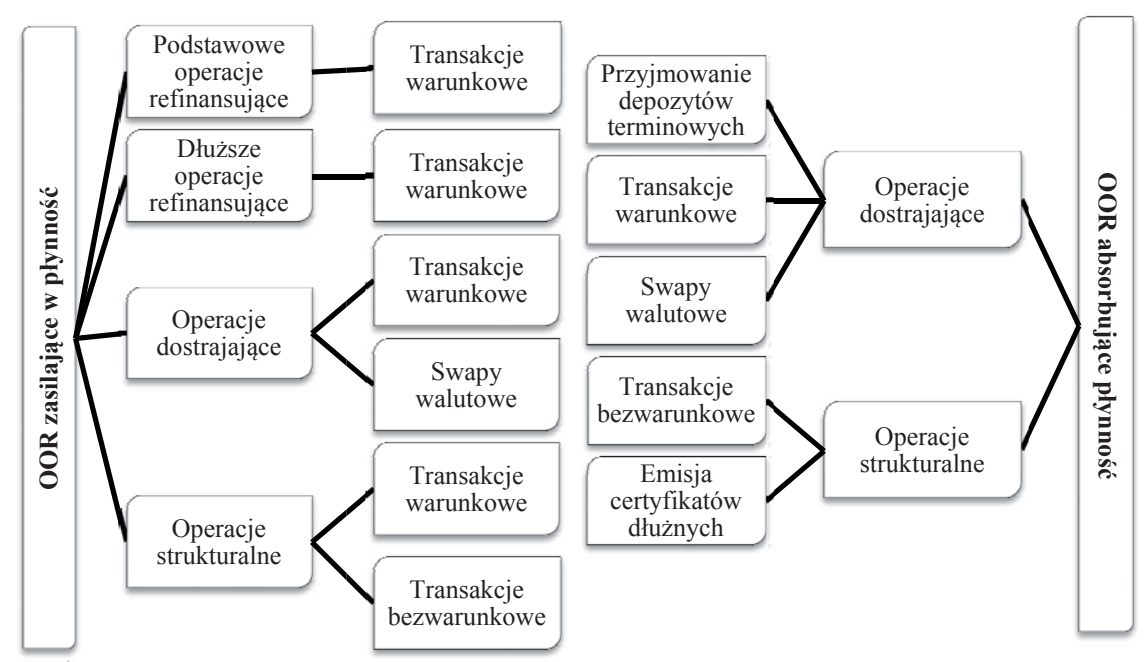

Rysunek 1. Rodzaje i formy operacji otwartego rynku w Eurosystemie

Źródło: opracowanie własne na podstawie: The implementation of monetary policy in the euro area: General Documentation on Eurosystem monetary policy instruments and procedures, EBC, Frankfurt am Main, November 2008, s. 14-19.

${ }^{5}$ The implementation of monetary policy in the euro area: General Documentation on Eurosystem monetary policy instruments and procedures, EBC, Frankfurt am Main, November 2008, s. 15.

${ }^{6}$ Ibidem, s. $14-15$.

${ }^{7}$ Ibidem, s. 12 . 
Dłuższe operacje refinansujące mają obecnie podstawowe znaczenie dla banków, gdyż w tej formie przeprowadzana jest większość operacji otwartego rynku w Eurosystemie. Nie sygnalizują one nastawienia w polityce monetarnej, lecz na ich podstawie władze monetarne Eurosystemu są informowane o oczekiwaniach rynków finansowych dotyczących kształtowania się stóp procentowych $\mathrm{w}$ przyszłości. Wynika to $\mathrm{z}$ tego, iż są one $\mathrm{z}$ reguły przeprowadzane $\mathrm{w}$ formie przetargu procentowego ${ }^{8}$, gdzie $\mathrm{EBC}$ występuje jako rate taker, wystawiając na aukcję określoną kwotę, a od kontrahentów przyjmuje oferty cenowe. Stopa procentowa kształtuje się więc w wyniku popytu ze strony banków, a wysokość zgłaszanych ofert odzwierciedla oczekiwania rynku w zakresie kształtowania się przyszłych stóp procentowych. Operacje te zostały wprowadzone głównie z myślą o mniejszych i mniej aktywnych podmiotach, które rozliczają się z rezerwy obowiązkowej w cyklu trzymiesięcznym oraz nie mają lub mają utrudniony dostęp do rynku międzybankowego ${ }^{9}$. LTRO są operacjami odwracalnymi, zasilającymi w płynność (repo), przeprowadzanymi w sposób zdecentralizowany przez krajowe banki centralne, raz w miesiącu (w ostatnią środę miesiąca) lub częściej. Termin zapadalności w tym przypadku standardowo wynosi trzy miesiące, choć zdarzają się operacje trzymiesięczne, roczne lub równe okresowi utrzymywania rezerwy obowiązkowej. Dostęp do dłuższych operacji refinansujących mają ci sami kontrahenci, którzy mogą uczestniczyć w podstawowych operacjach refinansujących. Lista zabezpieczeń jest również ta sama ${ }^{10}$.

W celu złagodzenia krótkotrwałych zaburzeń płynności (np. w ostatnim dniu utrzymywania rezerwy obowiązkowej, gdy podstawowe operacje otwartego rynku nie zrównoważyły płynności na rynku) EBC wprowadził operacje dostrajające, które cechują się dużym stopniem elastyczności w wyborze procedur i cech operacyjnych. W zależności od panującej nierównowagi płynnościowej w sektorze bankowym mogą to być operacje absorbujące płynność (przyjmowanie depozytów terminowych, transakcje warunkowe, swapy walutowe), przeprowadzane $w$ formie umów bilateralnych, lub w nią zasilające (transakcje warunkowe, swapy walutowe) kształtowane w wyniku przetargów szybkich ${ }^{11}$. Częstotliwość ich przeprowadzania oraz termin zapadalności nie są znormalizowane. Operacje fine-tuning zazwyczaj są przeprowadzane przez krajowe banki centralne ${ }^{12}$. Wszyscy kontrahenci

\footnotetext{
${ }^{8}$ Eurosystem może również przeprowadzić dłuższe operacje refinansujące w formie przetargów kwotowych.

${ }^{9}$ W. Przybylska-Kapuścińska, Eurosystem a instrumenty polskiej i czeskiej polityki pieniężnej, CeDeWu, Warszawa 2007, s. 42.

${ }^{10}$ The implementation of monetary policy in the euro area..., s. 15.

${ }^{11} \mathrm{~W}$ przypadku zasilających w płynność odwracalnych transakcji dostrajających dopuszcza się możliwość przeprowadzenia ich w formie umów bilateralnych.

${ }^{12} \mathrm{~W}$ wyjątkowych okolicznościach bilateralne odwracalne operacje mogą być przeprowadzone w sposób scentralizowany przez EBC.
} 
spełniający ogólne kryteria kwalifikacyjne mają dostęp do operacji dostrajających. Zabezpieczeniem tych operacji są aktywa rynkowe i nierynkowe ${ }^{13}$.

W przypadku długoterminowych zmian płynności sektora EBC może dokonać strukturalnej zmiany jego pozycji wobec systemu bankowego, przeprowadzając operacje strukturalne. $Z$ reguły są to operacje zasilające w płynność przeprowadzane w formie transakcji warunkowych lub bezwarunkowych. Jeśli wystąpi konieczność stworzenia (lub zwiększenia) niedoboru płynności na rynku, EBC może wykorzystać transakcje bezwarunkowe lub emisję certyfikatów dłużnych. W razie potrzeby operacje strukturalne mogą być przeprowadzane regularnie, lecz ich termin zapadalności nie jest z góry określony. Są one realizowane przez krajowe banki centralne w formie przetargów standardowych. Dostęp do tego instrumentu mają wszyscy kontrahenci, którzy są uprawnieni do korzystania z operacji podstawowych. Zabezpieczeniem w tym przypadku są aktywa rynkowe i nierynkowe ${ }^{14}$.

Podstawowym instrumentem wykorzystywanym $\mathrm{w}$ operacjach otwartego rynku w euroobszarze są transakcje warunkowe. Polegają one na kupnie lub sprzedaży aktywów kwalifikowanych w formie umów z przyrzeczeniem odkupu (repurchase agreement $)^{15}$ bądź na operacjach pożyczkowych zabezpieczonych tymi samymi aktywami (collateralised loan) ${ }^{16}$. Przy operacjach repo cena odkupu zawiera w sobie cenę sprzedaży powiększoną o wartość należnych, naliczonych odsetek za okres trwania transakcji. W przypadku pożyczki zabezpieczonej odsetki należne wynikają z umowy. Stopa procentowa stosowana w transakcjach warunkowych to prosta stopa procentowa powstała $z$ zastosowania formuły „dni faktyczne/360” 17 .

Transakcje bezwarunkowe zawierane są jedynie w celach strukturalnych i polegają na kupnie (outright purchase) lub sprzedaży (outright sale) aktywów kwalifikowanych bezpośrednio na rynku bez możliwości ponownego przeniesienia praw własności z kupującego na sprzedającego papiery wartościowe. Cena $\mathrm{w}$ tego typu transakcjach ustalana jest na podstawie powszechnie akceptowanych zwyczajów rynkowych odnośnie do instrumentów dłużnych. Częstotliwość operacji outright nie jest znormalizowana. Przeprowadzają je krajowe banki centralne w formie umów bilateralnych. Kontrahenci mają nieograniczony dostęp do transakcji warunkowych. Do zabezpieczenia tych transakcji używa się wyłącznie aktywów rynkowych ${ }^{18}$.

${ }^{13}$ The implementation of monetary policy in the euro area..., s. 16.

${ }^{14}$ Ibidem.

${ }^{15} \mathrm{~W}$ takim przypadku własność aktywów jest przenoszona na wierzyciela, a strony umawiają się na odwrócenie transakcji w przyszłości poprzez przeniesienie aktywów z powrotem na dłużnika.

${ }^{16}$ Zabezpieczeniem pożyczki jest prawo do dysponowania aktywami, ale prawo własności aktywów zachowuje dłużnik.

${ }^{17}$ The implementation of monetary policy in the euro area..., s. 17.

${ }^{18}$ Ibidem. 
Aby skorygować strukturalną nadpłynność sektora bankowego, EBC może emitować certyfikaty dłużne. Jest to zobowiązanie dłużne $\mathrm{EBC}$ wobec ich posiadacza wyemitowane i przechowywane $\mathrm{w}$ formie zapisów księgowych. Certyfikaty mogą być zbywane bez żadnych ograniczeń. Papiery te są emitowane z dyskontem (poniżej ceny nominalnej) i wykupywane w terminie zapadalności po cenie nominalnej. Kwota emisji liczona jest według wzoru $1^{19}$ :

$$
P_{T}=N \times \frac{1}{1+\frac{r_{I} \times D}{36.000}},
$$

gdzie:

$P_{T}$ - cena emisyjna,

$N$ - cena nominalna certyfikatu dłużnego,

$r_{I}$ - stopa procentowa ( $\left.\mathrm{w} \%\right)$,

$D$ - okres zapadalności certyfikatu dłużnego (w dniach).

Częstotliwość emisji certyfikatów może być regularna lub nieregularna. Ich termin zapadalności nie przekracza 12 miesięcy. Przetargi (zazwyczaj standardowe) i rozliczenie certyfikatów przeprowadzają krajowe banki centralne. Dostęp do przetargów mają wszystkie podmioty spełniające generalne kryteria kwalifi$\mathrm{kacji}^{20}$.

Swapy walutowe wykorzystuje się do absorpcji lub zasilenia w płynność w operacjach dostrajających. Ich mechanizm działania jest podobny do operacji warunkowych i polega na kupowaniu (sprzedawaniu) euro za obcą walutę ${ }^{21}$ po kursie kasowym i jednoczesnym odsprzedaniu (odkupywaniu) ich po kursie terminowym w określonym terminie. Strony operacji swapowych ustalają między sobą tzw. punkty swapowe (swap points), które odzwierciedlają różnicę między kursami walutowymi transakcji terminowej (forward $-\mathrm{F}_{\mathrm{M}}$ ) i transakcji kasowej $\left(\right.$ spot-S), według wzoru $2^{22}$ :

$$
\Delta_{M}=F_{M}-S=\frac{K_{F} \times X}{1 \times E U R}-\frac{K_{S} \times X}{1 \times E U R}=\frac{X \times\left(K_{F}-K_{S}\right)}{1 \times E U R},
$$

gdzie:

$\Delta_{M}$ - punkty terminowe między euro a walutą $\mathrm{X}$ na datę zapadalności swapu $(M)$,

$K_{F}\left(K_{S}\right)$ - kurs waluty $\mathrm{X}$ na rynku terminowym (kasowym),

$X, E U R$ - waluty uczestniczące w operacji swapowej.

\footnotetext{
${ }^{19}$ Ibidem.

${ }^{20}$ Ibidem.

${ }^{21} \mathrm{~S}$ ą to waluty powszechnie stosowane w praktyce handlowej.

${ }^{22}$ The implementation of monetary policy in the euro area..., s. 18.
} 
Wartość transakcji spot dla euro wynosi $N(E U R)=\frac{N(X)}{S}$ (dla waluty X: $N(X)=N(E U R) \times S)$, natomiast transakcji forward: $\quad N(E U R)_{M}=\frac{N(X)_{M}}{F_{M}} \quad$ (lub $\left.N(X)_{M}=N(E U R)_{M} \times F_{M}\right)$.

Termin przeprowadzania operacji swapowych nie jest ujednolicony. Przeprowadzają je krajowe banki centralne w formie przetargów szybkich ${ }^{23}$ lub EBC w formie umów bilateralnych. W gestii ECB pozostaje również wybór kontrahentów do swapów walutowych ${ }^{24}$.

Tabela 1. Procedury przeprowadzania operacji otwartego rynku w Eurosystemie

\begin{tabular}{|c|c|c|}
\hline CECHA & PRZETARG STANDARDOWY & PRZETARG SZYBKI \\
\hline Ramy czasowe & $\begin{array}{l}24 \text { godziny (od ogłoszenia przetar- } \\
\text { gu do potwierdzenia wyniku, nato- } \\
\text { miast od ostatecznego składania } \\
\text { ofert do ogłoszenia jego wyników } \\
\text { wpływa ok. } 2 \text { godziny) }\end{array}$ & $\begin{array}{l}90 \text { minut od ogłoszenia (potwier- } \\
\text { dzenie transakcji następuje nie- } \\
\text { zwłocznie po rozstrzygnięciu prze- } \\
\text { targu) }\end{array}$ \\
\hline Grupy kontrahentów & $\begin{array}{l}\text { wszyscy kontrahenci spełniający } \\
\text { ogólne kryteria kwalifikacji }\end{array}$ & $\begin{array}{l}\text { EBC może wybrać ograniczoną } \\
\text { liczbę kontrahentów }\end{array}$ \\
\hline Regularność i typy operacji & $\begin{array}{l}\text { zgodnie z kalendarzem publikowa- } \\
\text { nym przez Eurosystem (w przypad- } \\
\text { ku operacji podstawowych i dłuż- } \\
\text { szych operacji refinansujących) lub } \\
\text { nieregularnie w dowolnym dniu ro- } \\
\text { boczym (operacje strukturalne) }\end{array}$ & $\begin{array}{l}\text { nieregularnie w dowolnym dniu } \\
\text { roboczym (operacje dostrajające) }\end{array}$ \\
\hline
\end{tabular}

Rozliczenie operacji otwartego

rynku:

- transakcji warunkowych następny dzień roboczy

tego samego dnia roboczego

- transakcji bezwarunkowych

$-$

- certyfikatów dłużnych następny dzień roboczy

- swapów walutowych -

tego samego dnia lub w dniach

- depozytów terminowych _ _ _ t tego samego dnia

Źródło: opracowanie własne na podstawie: The implementation of monetary policy in the euro area..., s. 23-33.

Przyjmowanie depozytów terminowych ma na celu absorpcję płynności z rynku obszaru euro. Wybrani kontrahenci mogą złożyć niezabezpieczony de-

${ }^{23}$ Obecnie EBC przeprowadza operacje typu swap walutowy także w formie przetargów standardowych lub nie w ramach operacji fine-tuning.

${ }^{24}$ The implementation of monetary policy in the euro area..., s. 19. 
pozyt w krajowym banku centralnym ${ }^{25}$ na dowolny termin. Od wpłaconej kwoty naliczane jest stałe oprocentowanie za dni utrzymywania i wypłacane w dniu zapadalności depozytu. Realizuje się je w formie przetargów szybkich, wyjątkowo poprzez umowy bilateralne ${ }^{26}$. W Eurosystemie są dwa rodzaje przetargów: standardowe i szybkie. Różnice między nimi przedstawia tabela 1 na s. 265.

Przetargi standardowe i szybkie przebiegają według ściśle określonych procedur i składają się z sześciu następujących po sobie faz. Procedurę rozpoczyna $\mathrm{ECB}$, który ogłasza warunki przetargu ${ }^{27}$ krajowym bankom centralnym euroobszaru (etap 1a), te zaś informują kontrahentów bezpośrednio lub za pomocą systemów informacyjnych (etap 1b).

Następnie kontrahenci składają swoje oferty do krajowych banków centralnych (etap 2). Jeśli zaplanowany jest przetarg kwotowy (ze stałą stopą procentową), kontrahenci określają kwotę, na jaką chcą zawrzeć transakcję. W przetargach procentowych określają oni maksymalnie dziesięć poziomów stóp procentowych (będących wielokrotnością 0,01 punktu procentowego) i dla każdego podają kwotę transakcji. Kwota ta nie może być niższa niż $1 \mathrm{mln}$ euro i musi być podana jako wielokrotność 100 tys. euro. Wyjątkiem są dłuższe operacje refinansujące, gdzie oferta kwotowa musi się zawierać w przedziale od 10 tys. do $1 \mathrm{mln}$ i być wyrażona jako wielokrotność 10 tys. euro. EBC oprócz minimalnej kwoty może wprowadzić także górny limit oferty, aby uniknąć składania zbyt wysokich ofert ${ }^{28}$. Kontrahenci uczestniczący w przetargu muszą posiadać zadeklarowaną ilość eligible assets lub odpowiednią ilość płynnych rezerw, w przeciwnym przypadku krajowe banki centralne mają prawo nałożyć kary na podmioty niewywiązujące się ze złożonej przez siebie oferty.

W etapie trzecim dostarczone oferty są zestawiane przez krajowe banki centralne i w formie skumulowanej przesyłane do EBC. Następnie EBC podejmuje decyzję o rozstrzygnięciu przetargu (etap 4a) i ogłasza jego wynik (etap 4b). W przypadku przetargu kwotowego popyt na płynność ze strony instytucji kredytowych jest sumowany i jeśli przekracza on zaoferowaną przez EBC podaż

\footnotetext{
${ }^{25}$ Nawet gdy przyjmowanie depozytów terminowych odbywa się w sposób scentralizowany, przez EBC są one utrzymywane na rachunkach w krajowych bankach centralnych.

${ }^{26}$ The implementation of monetary policy in the euro area...

${ }^{27}$ Ogłoszenie zawiera takie informacje, jak: numer referencyjny operacji, datę jej przeprowadzenia, rodzaj operacji (zasilenie czy absorpcja) wraz z rodzajem instrumentu polityki pieniężnej, który ma być zastosowany, harmonogram składania ofert, termin zapadalności, rodzaj przetargu (kwotowy czy procentowy), sposób rozstrzygnięcia przetargu (aukcja holenderska czy amerykańska), przewidywana wielkość operacji lub stopa procentowa, minimalna wielkość indywidualnych przydziałów, minimalny współczynnik przydziału, górny limit oferty. W przypadku swapów walutowych informuje się także o walucie transakcji oraz walucie, w której kwota jest stała oraz referencyjny kurs kasowy. Kontrahenci zainteresowani certyfikatami dłużnymi powinni być również powiadomieni o nominale, kodzie emisji ISIN, dacie wyceny oraz terminie zapadalności.

${ }^{28}$ The implementation of monetary policy in the euro area..., s. 26.
} 
płynnych środków, kontrahenci są zaspokajani proporcjonalnie według wzoru $3^{29}$ :

gdzie:

$$
\text { all } \%=\frac{A}{\sum_{i=1}^{n} a_{i}},
$$

all\%- procent przyznanych środków,

$A$ - wielkość podaży środków oferowana przez EBC,

$a_{i}$ - wielkość popytu zgłaszanego przez $i$-tego kontrahenta,

$n$ - liczba kontrahentów uczestniczących w przetargu.

Wielkość przyznana $i$-temu kontrahentowi $\left(a l l_{i}\right)$ wynosi: all $_{i}=a l l \% \times\left(a_{i}\right)$.

W przypadku przetargu procentowego oferty partnerów w operacjach otwartego rynku są szeregowane malejąco (w przypadku operacji zasilających) lub rosnąco (w przypadku operacji absorbujących). EBC określa marginalną stopę, przy której dokona akceptacji ofert. Przy operacjach zwiększających (zmniejszających) płynność na rynku oferty ze stopą wyższą (niższą) są akceptowane w całości. Jeśli potrzeby płynnościowe przewyższają możliwości ich zaspokojenia przy marginalnej stopie procentowej, oferty są realizowane zgodnie ze wzorem $4^{30}$ :

$$
a l l \%\left(r_{m}\right)=\frac{A-\sum_{s=1}^{m-1} a\left(r_{s}\right)}{a\left(r_{m}\right)},
$$

gdzie:

all $\%\left(r_{m}\right)$ - procent przydziału po marginalnej stopie procentowej,

$r_{m-1}-$ stopa procentowa, przy której oferty są realizowane w całości,

$r_{s}-s$-ta stopa procentowa oferowana przez uczestników,

$r_{m}$ - krańcowa stopa procentowa,

$a\left(r_{s}\right)$ - łączna oferowana wielkość transakcji przy stopie $r_{3}$,

$a\left(r_{m}\right)$ - łączna oferowana wielkość transakcji przy stopie krańcowej.

W takim przypadku każdy uczestnik otrzyma środki skalkulowane wg równości 5:

$$
a l l_{i}=\sum_{s=1}^{m-1} a\left(r_{s}\right)_{i}+a l l \%\left(r_{m}\right) \times a\left(r_{m}\right)_{i},
$$

gdzie:

\footnotetext{
${ }^{29}$ Ibidem, s. 27.
}

${ }^{30}$ Ibidem, s. 28. 
$a\left(r_{s}\right)_{i}$ - wielkość oferowana przez $i$-tego uczestnika po stopie $r_{s}$

$a\left(r_{m}\right)_{i}$ - wielkość oferowana przez $i$-tego uczestnika po stopie $r_{m}$.

Po potwierdzeniu indywidualnych wyników przydziału i upublicznieniu wyników przetargu (etap 5) następuje ostatni etap - rozliczenie przetargu. Operacje otwartego rynku rozliczają krajowe banki centralne po ostatecznym transferze papierów wartościowych będących przedmiotem transakcji. Ramy czasowe rozliczania poszczególnych form operacji otwartego rynku zawiera tabela 1.

Oprócz procedur przetargowych Eurosystem może przeprowadzać operacje otwartego rynku z jedną lub kilkoma instytucjami kredytowymi naraz w formie umów bilateralnych (dotyczy to wyłącznie operacji dostrajających i bezwarunkowych operacji strukturalnych) w dwojaki sposób:

- przez pośrednika, jakim jest giełda papierów wartościowych lub animatorzy rynku,

- poprzez bezpośredni kontakt z kontrahentem(-ami).

Umowy bilateralne prowadzone przez pośrednika dotyczą transakcji bezwarunkowych. Przeprowadzane są z nieograniczoną liczbą partnerów wg powszechnie akceptowanych rynkowo procedur dotyczących instrumentów dłużnych. Bez udziału giełdy czy animatorów rynku przeprowadzane są transakcje warunkowe, bezwarunkowe, swapy walutowe i przyjmowanie depozytów terminowych. W takim przypadku krajowe banki centralne (a w wyjątkowych okolicznościach także EBC) kontaktują się bezpośrednio z podmiotami spełniającymi ogólne kryteria kwalifikujące i dodatkowo wykazują znaczną aktywność na rynku pieniężnym oraz dysponują dużym zasobem gotówkowym. Zamiaru przeprowadzenia umów dwustronnych, jak i ich wyników EBC zazwyczaj nie ogłasza publicznie ${ }^{31}$. Ramy czasowe rozliczenia operacji bilateralnych są podobne jak w przypadku przetargów szybkich (patrz tab. 1).

Charakterystykę operacji otwartego rynku Eurosystemu warto zakończyć kwestią zabezpieczeń. Status ESBC (art. 18.1) wymaga, aby wszystkie operacje kredytowe posiadały odpowiednie zabezpieczenie. W latach 1999-2006 istniały dwie kategorie aktywów kwalifikowanych: „aktywa z listy pierwszej” i „aktywa z listy drugiej”. Pierwsza kategoria zawierała wykaz instrumentów dłużnych spełniających jednolite dla całej strefy euro kryteria kwalifikacyjne określone przez EBC. Na liście drugiej znajdowały się aktywa dodatkowe, rynkowe i nierynkowe będące w obiegu na poszczególnych krajowych rynkach finansowych, akceptowane przez EBC. Aktywa $z$ obydwu list były traktowane na równi pod względem jakości i przydatności dla różnego rodzaju operacji polityki pieniężnej Eurosystemu (wyjątek: aktywa $\mathrm{z}$ tier two nie mogły być wykorzystywane w transakcjach

${ }^{31}$ Ibidem, s. 31. 
bezwarunkowych) ${ }^{32}$. Od 1 stycznia 2007 roku obowiązuje jednolity system zabezpieczeń zwany „wspólną listą”. Obejmuje ona aktywa rynkowe i nierynkowe, które spełniają jednolite kryteria kwalifikacji w strefie euro, określone przez $\mathrm{EBC}^{33}$. Aktywa rynkowe i nierynkowe są traktowane na równi pod względem jakości i możliwości ich wykorzystania w różnych operacjach polityki pieniężnej EBC (wyjątek stanowią transakcje bezwarunkowe, gdzie zabezpieczeniem nie mogą być aktywa nierynkowe). Wszystkie aktywa kwalifikowane można wykorzystywać w operacjach transgranicznych, a w przypadku aktywów rynkowych przez odpowiednie powiązania między wspólnotowymi systemami rozrachunku papierów wartościowych ${ }^{34}$.

\section{OPERACJE OTWARTEGO RYNKU W POLSCE}

Operacje otwartego rynku wykorzystywane przez NBP służą do utrzymywania krótkoterminowych stóp procentowych na poziomie spójnym z utrzymaniem inflacji jak najbliżej poziomu $2,5 \%$. Poprzez operacje otwartego rynku bank centralny w Polsce oddziałuje na płynność sektora bankowego w taki sposób, aby stawka POLONIA (Polish Overnight Index Average) ${ }^{35}$ kształtowała się w pobliżu stopy referencyjnej $\mathrm{NBP}^{36}$.

Podstawą prawną przeprowadzania operacji otwartego rynku w Polsce jest Ustawa o Narodowym Banku Polskim, która daje prawo bankowi centralnemu do emisji i sprzedaży papierów wartościowych, sprzedaży i kupna dłużnych papierów wartościowych w operacjach otwartego rynku, a także do organizowania obrotu papierami wartościowymi własnej emisji oraz papierami skarbowymi ${ }^{37}$. Szczegó-

${ }^{32}$ B. Mucha-Leszko, Strefa euro: wprowadzenie, funkcjonowanie, międzynarodowa rola euro, Wydawnictwo UMCS, Lublin 2007, s. 137.

${ }^{33}$ Do kryteriów tych należą: jakość kredytowa, miejsce emisji, procedury rozliczenia/obsługi, rodzaj emitenta, miejsce ustanowienia emitenta, akceptowane rynki, waluta, minimalna wielkość, właściwość prawna, wykorzystanie transgraniczne (zob. Realizacja polityki..., s. 43).

${ }^{34}$ M. Proczek, Polityka monetarna w strefie euro, „Bank i Kredyt” 2008, nr 6, dodatek edukacyjny, s. 24.

${ }^{35}$ Stopa ta wprowadzona została w 2005 r. i jest polskim odpowiednikiem eurosystemowej stawki EONIA. Jest to średnia stawka overnight ważona wielkością transakcji na rynku depozytów bankowych. Poziom jej informuje o rzeczywistym oprocentowaniu lokat międzybankowych na koniec dnia. Do 2007 r. (od 2005 r.) celem NBP było utrzymywanie stawki WIBOR SW w pobliżu stopy referencyjnej, lecz ze względu na wzrost udziału lokat overnight w całości obrotów na rynku niezabezpieczonych lokat międzybankowych zastąpiono ją stopą POLONIA.

${ }^{36}$ Zatożenia polityki pieniężnej na 2009, NBP, Warszawa 2008, s. 15.

${ }^{37}$ Ustawa z dnia 29 sierpnia 1997 r. o Narodowym Banku Polskim, Dz. U. z 1997 r., nr 140, poz. 938 , art. 48 . 
łowe regulacje dotyczące omawianego instrumentu określają Uchwały Rady Polityki Pieniężnej i Zarządu NBP zawarte w Dziennikach Urzędowych NBP.

Dostosowując swoje instrumentarium do norm panujących w obszarze euro, NBP wprowadził podział operacji otwartego rynku na trzy rodzaje: podstawowe, dostrajające i strukturalne ${ }^{38}$.

Podstawowe operacje wyznaczają kierunek polityki pieniężnej i od 1 stycznia 2009 roku polegają one na emisji bonów pieniężnych NBP oraz przeprowadzaniu operacji repo. Przeprowadzane są one w formie przetargu raz w tygodniu (w piątek), a ich termin zapadalności wynosi siedem dni ${ }^{39}$. Ich zabezpieczeniem są papiery wartościowe akceptowane przez NBP. Wprowadzenie operacji warunkowych miało stanowić wentyl bezpieczeństwa w razie wystąpienia niedoboru płynności w sektorze bankowym. Termin zapadalności bonów pieniężnych NBP uległ skróceniu na przestrzeni lat. Do 1 stycznia 2003 roku wynosił on dwadzieścia osiem dni ${ }^{40}$, następnie czternaście dni ${ }^{41}$. Od 1 stycznia 2005 roku NBP w ramach podstawowych operacji otwartego rynku emituje bony 7-dniowe ${ }^{42}$. Przez dłuższy czas emisja 28-dniowych operacji otwartego rynku była nieregularna. Banki komercyjne miały możliwość lokowania nadwyżek swoich płynnych środków nawet codziennie, co jednak nie jest korzystne z punktu widzenia zarządzania płynnością i rozwoju rynku międzybankowego. Dopiero od 31 stycznia 2002 roku podstawowe operacje NBP przeprowadzane są raz w tygodniu (w piątek), czyli w sposób regularny ${ }^{43}$. Rentowność operacji podstawowych wyznacza RPP, kształtując stopę referencyjną. W instrumentarium NBP nie występuje odpowiednik regularnych dłuższych operacji przeprowadzanych przez EBC.

Aby ograniczyć wpływ zmian w warunkach płynnościowych w sektorze bankowym na wysokość krótkoterminowych rynkowych stóp procentowych, NBP może przeprowadzić operacje dostrajające. Skonstruowano je tak, aby umożliwić bankowi centralnemu jak najszybszą i najbardziej skuteczną interwencję. $Z$ tego względu mogą być one przeprowadzane incydentalnie, w dowolnej częstotliwości, mogą działać w stronę zasilania lub zmniejszenia płynności na rynku, termin ich zapadalności także nie jest $\mathrm{z}$ góry określony. Polegają one na emisji bonów

${ }^{38}$ Pomysł ten zasygnalizowano już w Zatożeniach polityki pieniężnej na 2002 rok, NBP, Warszawa 2001, s. 13-14. Formalnie podział ten wcieliła w życie Uchwała nr 1/2002 RPP z dnia 29 stycznia 2002 r. w sprawie zasad prowadzenia operacji otwartego rynku, Dz. Urz. NBP z 2002 r., nr 2, poz. 2.

${ }^{39}$ Częstotliwość oraz zapadalność podstawowych operacji otwartego rynku może zostać zmieniona $\mathrm{w}$ razie potrzeby.

${ }^{40}$ Uchwała nr $1 / 2002$ RPP..., § 1 ust. 1.

${ }^{41}$ Uchwała nr 20/2002 RPP z dnia 17 grudnia 2002 r. w sprawie zasad prowadzenia operacji otwartego rynku, Dz. Urz. NBP z 2002 r., nr 20, poz. 52, § 1 ust. 1.

${ }^{42}$ Uchwała nr 14/2004 RPP z dnia 14 grudnia 2002 r. w sprawie zasad prowadzenia operacji otwartego rynku, Dz. Urz. NBP z 2004 r., nr 21, poz. 39, § 1 ust. 1.

${ }^{43}$ Uchwała nr 1/2002 RPP..., § 1 ust. 1. 
pieniężnych, przedterminowym ich wykupie lub przeprowadzaniu operacji repo i reverse repo ${ }^{44}$. Mogą być przeprowadzane w formie przetargów (w szczególnych przypadkach na podstawie umów między NBP a bankami). Ich rentowność może być inna od stopy referencyjnej NBP i ustalana jest na przetargach lub w ww. umowach. Od 1998 roku operacje dostrajające polegały na przeprowadzaniu operacji otwartego rynku na terminy niestandardowe (1, 7, 14 dni). Większość emisji została przeprowadzona w grudniu 1999 roku, aby złagodzić wahania płynności, jakie mogły nastąpić w związku z tzw. efektem millenium. W tym okresie banki nie były w stanie oszacować długoterminowego zapotrzebowania na gotówkę oraz skali wypłat $\mathrm{z}$ rachunków ludności i obawiały się zamrażania płynności w bonach miesięcznych w podstawowych operacjach otwartego rynku. NBP emitował wówczas bony o krótszym okresie zapadalności, tym samym zapobiegł spadkowi stopy WIBOR $1 \mathrm{M}$ poniżej wyznaczonego przez siebie poziomu ${ }^{45}$. Od 31 stycznia 2002 roku, czyli od momentu podziału operacji otwartego rynku na trzy rodzaje, operacje dostrajające nie były przeprowadzane. W 2008 roku w ramach realizacji „Pakietu zaufania” NBP rozpoczął przeprowadzanie operacji repo zasilających w płynność. W okresie październik 2008-lipiec 2009 roku przeprowadzono 22 operacje repurchase agreements na łączną kwotę $60179,5 \mathrm{mln} \mathrm{zt}^{46}$. W ramach operacji dostrajających NBP dokonał również sprzedaży bonów pieniężnych na okresy krótsze od terminu zapadalności operacji podstawowych (2-dniowe i 3-dniowe), aby zapobiec dalszemu spadkowi stawki POLONIA w wyniku powstania znaczącej nadwyżki płynności w tym okresie. Operacje te nie zostały już powtórzone.

NBP może dokonać długoterminowej zmiany płynności w sektorze bankowym, przeprowadzając operacje strukturalne, które polegają na: emisji obligacji NBP lub ich przedterminowym wykupie oraz zakupie i sprzedaży papierów wartościowych na rynku wtórnym. W 1999 roku została przeprowadzona konwersja niezbywalnych zobowiązań Skarbu Państwa wobec NBP na zbywalne obligacje skarbowe o zapadalności 2, 3, 4, 5 i 10 lat. We wrześniu 2000 roku NBP rozpoczął aukcyjną sprzedaż tych obligacji o łącznej wartości nominalnej 16,4 mld zł, którą zakończył 17 kwietnia 2003 roku. Ograniczenie płynności z tytułu sprzedaży obligacji skonwertowanych w latach 2001-2003 wynosiło 10,735 $\mathrm{mld} \mathrm{zt}^{47}$. Dnia

${ }^{44}$ Uchwała nr 20/2008 RPP z dnia 23 grudnia 2008 r. w sprawie zasad prowadzenia operacji otwartego rynku, Dz. Urz. NBP z 2008 r., nr 25, poz. 32, § 1 ust. 2.

${ }^{45}$ O. Szczepańska, Operacje otwartego rynku jako element systemu operacyjnego EBC i banków centralnych w krajach kandydujacych do Unii, „Bank i Kredyt” 2002, nr 4, s. 14.

${ }^{46}$ Informacja wstepna nr 2/2009, NBP, Warszawa 2009, s. 6.

47 Operacje otwartego rynku na tle ptynności sektora bankowego 2001, dokument internetowy, NBP, Warszawa 2002, s. 2; Operacje otwartego rynku na tle ptynności sektora bankowego 2002, dokument internetowy, NBP, Warszawa 2003, s. 1; Instrumenty polityki pieniężnej na tle ptynności sektora bankowego w 2003 r., NBP, Warszawa 2004, s. 16. 
22 stycznia 2009 roku NBP przeprowadził wykup własnych obligacji na kwotę 8,3 mld zł, co spowodowało zwiększenie płynności sektora bankowego w lutym o $5,3 \mathrm{mld} \mathrm{zt}^{48}$.

Operacje otwartego rynku w Polsce mogą być przeprowadzane w trybie przetargowym lub w szczególnych przypadkach w trybie pozaprzetargowym. W tym drugim przypadku warunki transakcji określane są na podstawie umowy między NBP a bankiem. W trybie przetargowym dokonuje się: sprzedaż i przedterminowy wykup bonów pieniężnych, zawieranie $\mathrm{z}$ bankami umów repo na papierach wartościowych oraz transakcji outright odnoszących się do skarbowych papierów wartościowych ${ }^{49}$.

W podstawowych operacjach może uczestniczyć Bankowy Fundusz Gwarancyjny oraz banki, które: uczestniczą bezpośrednio w systemie SORBNET (jest to system obsługi rachunków bankowych w NBP) i Rejestrze Papierów Wartościowych oraz posiadają moduł ELBON (jest to oprogramowanie, jakie banki uczestniczące w RPW dostają od NBP; służy do składania zleceń oraz odbierania komunikatów z Departamentu Operacji Krajowych NBP) ${ }^{50}$. Od 7 listopada 2008 roku operacje dostrajające są przeprowadzane ze wszystkimi bankami spełniającymi warunki niezbędne do uczestnictwa w operacjach podstawowych ${ }^{51}$. W operacjach strukturalnych wyboru dokonuje każdorazowo Zarząd NBP ${ }^{52}$.

Przetarg, organizowany przez Departament Operacji Krajowych, składa się z sześciu następujących po sobie faz. Rozpoczyna się on od przekazania zainteresowanym bankom informacji o terminie przetargu, typie, wielkości, terminie zapadalności transakcji oraz rodzaju oferowanych papierów wartościowych, za pośrednictwem systemów informacyjnych (np. poprzez Reuters). W etapie drugim uczestnicy przetargu wysyłają do DOK prawidłowo sporządzoną pod względem formalnym i rachunkowym ofertę. Wartość nominalna oferty musi

${ }^{48}$ Biuletyn informacyjny 2/2009, NBP, Warszawa 2009, s. 9.

${ }^{49}$ Uchwała nr 66/2005 Zarządu NBP z dnia 9 grudnia 2005 r. zmieniająca uchwałę w sprawie wprowadzenia „Regulaminu prowadzenia przez Narodowy Bank Polski rachunków i kont depozytowych papierów wartościowych oraz obsługi operacji na papierach wartościowych i ich rejestracji na rachunkach i kontach depozytowych tych papierów”, Dz. Urz. NBP z 2005 r., nr 20, poz. 27, § 1 ust. 11; Uchwała nr 47/2008 Zarządu NBP z dnia 9 grudnia 2005 r. zmieniająca uchwałę w sprawie wprowadzenia „Regulaminu prowadzenia przez Narodowy Bank Polski rachunków i kont depozytowych papierów wartościowych oraz obsługi operacji na papierach wartościowych i ich rejestracji na rachunkach i kontach depozytowych tych papierów”, Dz. Urz. NBP z 2008 r., nr 18, poz. 22, § 1; Uchwała nr 29/2009 Zarządu NBP z dnia 9 grudnia 2005 r. zmieniająca uchwałę w sprawie wprowadzenia „Regulaminu prowadzenia przez Narodowy Bank Polski rachunków i kont depozytowych papierów wartościowych oraz obsługi operacji na papierach wartościowych i ich rejestracji na rachunkach i kontach depozytowych tych papierów”, Dz. Urz. NBP z 2009 r., nr 7, poz. 27, § 1 ust. 3.

${ }^{50}$ Uchwała nr 66/2005 Zarządu NBP..., § 1 ust. 11.

${ }^{51}$ Sprawozdanie z realizacji polityki pieniężnej w 2008 r., NBP, Warszawa 2009, s. 25.

${ }^{52}$ Uchwała nr 66/2005 Zarządu NBP..., § 1 ust. 11, pkt 5. 
wynosić $1 \mathrm{mln}$ zł lub wielokrotność tej kwoty w odniesieniu do papierów wartościowych danego rodzaju i o danym terminie wykupu (nie dotyczy to ofert na transakcje repo $)^{53}$.

W trzecim etapie NBP określa kryterium wyboru ofert, które zostaną zrealizowane, i rozstrzyga przetarg. Ma on przy tym prawo do przyjęcia części lub żadnej propozycji zawarcia transakcji bez podawania przyczyn. Decyzję swą obwieszcza za pomocą systemów informacyjnych (np. Reuters) w formie zbiorowej (faza czwarta przetargu). Po rozstrzygnięciu przetargu przekazywane są każdemu uczestnikowi indywidualnie zawiadomienia o przyjęciu bądź odrzuceniu złożonej oferty (etap piąty) $)^{54}$.

Uczestnik przetargu musi posiadać odpowiednią ilość środków na rachunku bankowym lub wystarczającą ilość papierów wartościowych, które były przedmiotem oferty na rachunku w RPW albo na rachunku na koncie depozytowym w Krajowym Depozycie Papierów Wartościowych, aby przetarg mógł być rozstrzygnięty. Rozstrzygnięcie przetargu (etap ostatni) może przyjąć jedną z poniższych form:

- zapłata w terminie określonym w informacji o przetargu za papiery wartościowe będące jego przedmiotem w drodze odpowiednich zapisów księgowych na koncie kontrahenta i koncie ewidencjonującym zobowiązania NBP;

- obciążenie lub uznanie rachunku bankowego uczestnika przetargu na podstawie zleceń wystawionych przez NBP (w sytuacji, gdy przedmiotem operacji są bony pieniężne lub zagraniczne papiery wartościowe) bądź KDPW na podstawie dowodów ewidencyjnych otrzymanych od NBP (gdy przedmiotem operacji są obligacje skarbowe lub inne papiery wartościowe);

- obciążenie rachunku bankowego banku na podstawie upoważnienia wystawionego dla NBP przez RPW kwotami wynikającymi ze zrealizowania operacji na papierach wartościowych;

- rejestracja, wraz z zapłatą, papierów wartościowych będących przedmiotem przetargu na odpowiednich rachunkach w RPW lub rachunkach i kontach depozytowych w KDPW 55 .

W sytuacji, gdy uczestnik nie może wywiązać się ze złożonej przez siebie oferty, NBP ma prawo do nałożenia na niego sankcji, m.in. może zostać zawieszone przyjmowanie ofert danego kontrahenta na okres do 12 miesięcy $^{56}$.

${ }^{53}$ Uchwała nr 29/2009 Zarządu NBP..., § 1 ust. 4, pkt a.

${ }^{54}$ Uchwała nr 29/2003 Zarządu NBP z dnia 9 grudnia 2005 r. zmieniająca uchwałę w sprawie wprowadzenia „Regulaminu prowadzenia przez Narodowy Bank Polski rachunków i kont depozytowych papierów wartościowych oraz obsługi operacji na papierach wartościowych i ich rejestracji na rachunkach i kontach depozytowych tych papierów”, Dz. Urz. NBP z 2003 r., nr 15, poz. $23, \S 26$ ust. $6-7$.

${ }^{55}$ Uchwała nr 29/2009 Zarządu NBP..., § 1 ust. 7.

${ }^{56}$ Więcej na ten temat w: Uchwała nr 29/2009 Zarządu NBP..., § 1 ust. 8. 
Od początku stosowania operacji otwartego rynku w Polsce jako zabezpieczenie akceptowano tylko skarbowe papiery wartościowe. Poprzez zmianę w zapisie Ustawy o NBP, polegającą na zastąpieniu słowa skarbowe przymiotnikiem dtużne, NBP ma zielone światło do posługiwania się papierami wartościowymi spełniającymi jego standardy. Od maja 2009 roku zakres zabezpieczeń dla operacji dostrajających uległ rozszerzeniu o inne niż skarbowe dłużne papiery wartościowe zdeponowane w KDPW, papiery wartościowe nominowane w walutach obcych czy papiery skarbowe emitowane $\mathrm{z}$ kuponem. Banki będą miały także możliwość ponownego wykorzystania danego zabezpieczenia w operacji dostrajającej tego samego dnia, w którym upływa jego zapadalność w operacji poprzedniej (tzw. netting $)^{57}$.

\section{ZAKOŃCZENIE}

Harmonizacji ze standardami EBC wymagają wszystkie rodzaje przeprowadzonych przez NBP operacji na otwartym rynku. W zakresie operacji podstawowych dostosowania rozpoczęły się w 2002 r., kiedy to zadecydowano, że będą się one odbywały raz w tygodniu, czyli z taką częstotliwością jak w Eurosystemie. Od początku 2005 roku mają one taki sam termin zapadalności - 7 dni. Od 1 stycznia do marca 2004 roku, kiedy to w Eurosystemie skrócono termin zapadalności z dwóch do jednego tygodnia, rozwiązanie w Polsce odpowiadało europejskiemu. Od marca do końca 2004 roku znów wystąpiło niedostosowanie. Skrócenie terminu zapadalności można było przeprowadzić przy umiarkowanej skali nadpłynności sektora bankowego. Zwiększyło to elastyczność przeprowadzania operacji otwartego rynku, gdyż umożliwiło zamrażanie płynności na krótsze okresy oraz zapadalność większej liczby emisji w ciągu jednego okresu utrzymywania rezerwy obowiązkowej. Tym samym mogły z nich korzystać mniej płynne i mniejsze banki. Dostosowaniu musi także ulec kierunek przeprowadzania podstawowych operacji otwartego rynku. Wymaga to jednak przejścia z nadpłynności do niedoboru płynności w polskim systemie bankowym. W przypadku pojawienia się niedoboru płynności NBP ma prawo wykorzystać operacje repo ${ }^{58}$. Skala dostosowań operacji podstawowych do rozwiązań euroobszaru jest więc zadowalająca. Warto wspomnieć także o kwestii rentowności operacji podstawowych. Ze względu na odmienną sytuację płynnościową w Polsce (nadpłynność) w porównaniu z euroobszarem (niedobór płynności) NBP, określając rentowność OOR, wykazuje tym samym najmniejszy zysk, jaki mogą zrealizować banki zawierające transakcje,

${ }^{57}$ Harmonogram operacji otwartego rynku oraz typu swap walutowy w dniach 1 kwietnia-30 czerwca $2009 r$. (dokument internetowy).

${ }^{58}$ Ibidem. 
a EBC (jeśli stosuje zmienną stopę procentową) najniższy koszt, po jakim zwiększą swoją płynność.

W instrumentarium NBP nie figurują natomiast dłuższe operacje refinansujące używane przez EBC. Wprowadzenie ich wymagałoby uprzedniego zasygnalizowania w Zatożeniach polityki pieniężnej, a także zmiany uchwały RPP w sprawie zasad prowadzenia operacji otwartego rynku. Ze względu na wciąż utrzymującą się nadpłynność sektora bankowego, implementacja operacji dla instrumentów o 3-miesięcznym terminie zapadalności nie wydaje się uzasadniona. Mogłaby być to emisja 3-miesięcznych bonów pieniężnych, operacje reverse repo $0^{59}$ lub przeprowadzanie absorbujących operacji podstawowych i dłuższych zasilających.

Operacje dostrajające mają wiele cech wspólnych $\mathrm{z}$ odpowiadającymi im transakcjami europejskimi - mogą dwukierunkowo oddziaływać na sytuację płynnościową oraz stosowane są zazwyczaj nieregularnie. Jednakże lista wykorzystywanych narzędzi w ramach transakcji dostrajających jest dosyć wąska. Nie występują na niej swapy walutowe ani przyjmowanie depozytów terminowych w banku centralnym. Choć NBP przeprowadza operacje typu swap na parach walut EUR/PLN oraz USD/EUR, to jednak formalnie transakcje te nie należą do operacji otwartego rynku. Implementacji wyżej wymienionych instrumentów nie przewiduje Ustawa o NBP.

Pierwotnie przyjęte rozwiązania dotyczące operacji strukturalnych NBP przewidywały wąski, w porównaniu $\mathrm{z}$ europejskim, zakres ich form. Jednak od 2002 roku był on dwukrotnie rozszerzany. Pierwotnie umożliwiały one jedynie absorpcję płynności w ramach bezwarunkowej sprzedaży obligacji skarbowych przez NBP. Następnie wprowadzono także operacje zasilające. NBP nie przeprowadza omawianego instrumentu $\mathrm{w}$ formie operacji warunkowych oraz emisji certyfikatów dłużnych, choć ma on możliwość w ramach operacji strukturalnych emisji długoterminowych papierów dłużnych, a termin zapadalności certyfikatów EBC wynosi 12 miesięcy. Dostosowanie w tym kierunku wymagałoby opracowania procedur dla ich stosowania oraz sankcjonujących ich wprowadzenie uchwał zarządu NBP i RPP.

W zakresie procedur przeprowadzania operacji otwartego rynku istnieje kilka kwestii, które muszą przejść reformę. W warunkach polskich nie ma bowiem rozróżnienia przetargów standardowych i szybkich, stosowanych przy operacjach dostrajających. Nie jest także jasno sprecyzowane, w jakich sytuacjach dopuszczalne jest przeprowadzenie operacji otwartego rynku w trybie pozaprzetargowym. W Eurosystemie tryb pozaprzetargowy stosuje się zazwyczaj przy niestandardowej sytuacji płynnościowej, gdzie oczekiwana jest szybka reakcja ze strony EBC.

\footnotetext{
${ }^{59}$ Rozwiązanie takie prawnie uregulowane jest w Czechach, jednak nie jest wykorzystywane od $2001 \mathrm{r}$.
} 
Tryb pozaprzetargowy w Polsce określany jest jako quasi-umowy dwustronne, a w przepisach prawnych nie występuje określenie umowy bilateralnej.

\section{THE ADJUSTMENT OF INSTRUMENTS OF THE NATIONAL BANK OF POLAND TO THE STANDARDS OF THE EUROSYSTEM - OPEN MARKET OPERATIONS}

SUMMARY

The idea of the EMU requires countries entering the euro zone to have a homogeneous system of monetary policy instruments including open market operations. This paper presents a comparative analysis of Polish and European zone solutions in the range of open market operations. The purpose of this analysis is to determine the degree of adjustment of the instruments discussed, used by the National Bank of Poland to the standards, norms and procedures of the European Central Bank. The adjustment requires the harmonization of all types carried out by the Polish National Bank operations on the open market. 